\title{
CORRELATION AND MULTIPLE REGRESSION ANALYSIS OF THE CENTRAL INCISORS AND GINGIVAL COLOR RELATIONSHIP
}

\author{
Mohamed Ahmed Alkhodary*
}

\begin{abstract}
Introduction The color of the gingiva was thought to be a valuable assist in determining the color of the missing central incisors. The aim of this study was to investigate the correlation between CIE L*a*b* color coordinates of central incisor teeth and attached gingiva.
\end{abstract}

Materials and methods Two hundred patients participated in this study, the color coordinates $\mathrm{L} * \mathrm{a} * \mathrm{~b} *$ of the central incisors and attached gingiva were determined by the clinical spectrophotometer Shadepilot, Pearson's correlation and multiple regression were used to assess whether one can predict the value of the tooth color coordinates based on the values of gingival color.

Results The results of current work showed significant correlation of the teeth color to gingival color, except for the maxillary central incisor $\mathrm{a}^{*}$, and showed that gingival color can be used to predict the color of missing central incisor teeth.

Conclusion Within the limitation of this study, it was concluded that a significant correlation existed between central incisors and gingival color.

KEYWORDS: Attached gingiva color, CIELAB color system, Spectrophotometer, Tooth color.

\section{INTRODUCTION}

Relatively good amount of data exists regarding the relationship of skin and teeth color, and the effect of gender and age on it. ${ }^{1-10}$ Some studies suggested a significant negative relationship between skin color and tooth shade, where people with light color skin would have teeth with dark shades and people with dark skin would have whiter teeth, also, women were found to have lighter teeth color than men..$^{1-3,7,8}$ Other studies suggested a significant relationship of skin and tooth color as related to age, where teeth and skin darken as they get more yellow and red components. ${ }^{5}$ On the contrary, studies tried to investigate the skin to tooth color relationship, as a reference for selecting teeth for partially or completely edentulous patients, suggested that the dentist should not consider the patient gender or complexion as fixed rules. ${ }^{6,9,10}$

Remaining teeth, attached gingiva, and eye colors present additional references for missing teeth color. ${ }^{11-19}$ Adjacent and opposing teeth were found to have a significant color relationship. ${ }^{11}$

\footnotetext{
* Associate Professor, Department of Prosthodontics, Faculty of Dentistry, Alexandria University, Egypt.
} 
Gingival color, was related to skin color, with more pigmentation associated with darker skin, in men more than women, and with the pigments being located in the attached gingiva, more in the interdental papillae rather than the free gingival margin. ${ }^{12,13,17}$ The eye color was found not to be related to teeth color, ${ }^{15}$ however, this was claimed only in relation to the lateral incisors and canines. ${ }^{18}$ Obviously these findings represent a challenge to prosthodontists when trying to harmonize the color of teeth in the prostheses provided to the patients, and require adequate training and understanding of the principles of the visual and digital tooth shade determination. ${ }^{14,16,19}$

Several color space systems are available to describe color, with the Munsell and CIE systems being the most widely used, the Munsell system describes color in three dimension using three coordinates, the hue, value, and chroma, on the other hand, the CIE system uses three coordinates, $\mathrm{L}^{*} \mathrm{a}^{*}$ $\mathrm{b}^{*}$, to describe color where $\mathrm{L}^{*}$ is the lightness axis from black to white, $a^{*}$ is the red-green axis, $b^{*}$ is the yellow-blue axis, and $\Delta \mathrm{E}$ is the color difference value that represents the color perception; only $\Delta \mathrm{E}$ values between 1 and 2 are considered clinically acceptable, whereas values above or less than these would implicate a high degree of intra- and interexaminer variability, and render the use of digital shade matching devices more useful to minimize the subjectivity of color assessment. ${ }^{20-29}$

Gingival color was found to be related to gender, age, and skin color of different ethnic origins, however, very little data exists regarding the color relation between the gingiva and the teeth. 30-33 Different gingival colors and pigmentations, and inadequacy of available gingival visual shade guides further complicate the situation and hinder the clinician from further investigations into pink esthetics. Compared to visual color assessment, the digital color evaluation using spectrophotometers can provide numerical values of the 3 dimensions of the color, and help the clinicians to have specific references of color coordinates, and since the
CIELAB system provides objective measurements of color of dental structures, and allows the color differences to be expressed in units, ${ }^{34-38}$ this study aimed at finding the correlation between the color of the maxillary and mandibular central incisors to the color of the maxillary attached gingiva, and used multiple regression analysis in a trial to find out how much of the color coordinates of these incisors can be predicted using the color coordinates of the maxillary attached gingiva.

\section{MATERIALS AND METHODS}

Two hundred patients and students (100 males and 100 females, 20-30 years old) at the college of dentistry of Qassim university in the kingdom of Saudi Arabia were recruited via convenience sampling. The following patients were excluded from the study: individuals with discolored, bleached or restored anterior teeth, individuals with inflamed attached gingiva, or had gingival depigmentation, and smokers. Written informed consents were obtained from every participant. The study was conducted in full accordance with the World Medical Association Declaration of Helsinki.

The study was conducted at the screening clinic of Qassim University's dental clinics, and the same ambient conditions were maintained throughout the duration of the study (i.e., fluorescent ceiling light as the ambient lighting and a location away from windows).

The color attributes in CIE $\mathrm{L}^{*} \mathrm{a} * \mathrm{~b} *$ color space were measured for the middle third of the right or left maxillary and mandibular central incisors, and for the maxillary attached gingiva, at a point $2 \mathrm{~mm}$ apical to the zenith of cervical line of the maxillary central incisors, using an intraoral spectrophotometer (Shadepilot; DeguDent GmbH, Hanau, Germany). The device was operated according to the manufacturer's instructions and always calibrated for each individual before any measurements are obtained. The participants' teeth were polished to remove any extrinsic stains prior 
to starting the experimental procedures. All of the measurements were made by the same examiner. The CIE L*a*b* measurements were made twice for each location (tooth, gingiva) and the average of each of the color attributes $\mathrm{L}^{*}, \mathrm{a}^{*}$ and $\mathrm{b}^{*}$ were tabulated for the statistical analysis.

To measure the strength of the linear relation between the CIE L*a*b* color coordinates of teeth and gingiva, Pearson's correlation was used. Multiple regression was used to assess whether one can predict the value of the tooth color coordinates based on the values of gingival color. All of analyses were performed using SPSS software (SPSS 22 for Windows; IBM Corporation, Armonk, NY, USA). The level of significance was set at $\mathrm{p}<0.05$.

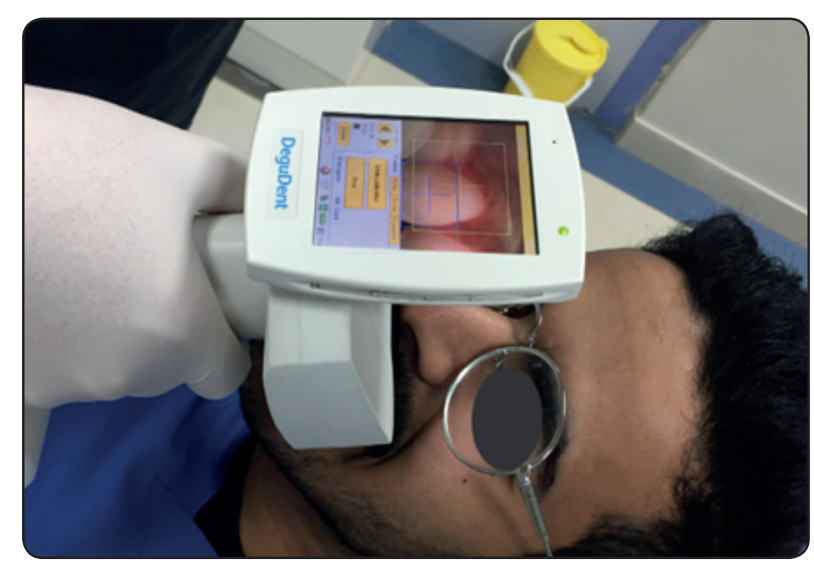

Fig. (1) The use of the Shadepilot to measure the color coordinates of the teeth and attached gingiva.

\section{RESULTS}

Figures 2-7 show the distribution of the color coordinates studied, and table 1 shows the mean CIE $\mathrm{L}^{*} \mathrm{a} \mathrm{b}^{*}$ values for the maxillary and mandibular central incisors, and the attached gingiva in male and female patients.

The $\mathrm{L}^{*}$ mean value for the male maxillary central incisor 88.16 (5.96) was higher than that of the mandibular central incisor 85.49(7.10), however, its a* 3.01 (3.44) and b* 12.54 (6.30) means were less than those of the lower incisor being 4.89 (3.64) and 13.21 (7.71) respectively. The male attached gingiva $\mathrm{L}^{*}$ mean value 63.74 (9.35) was less than those of the incisors, however, its means of a* 29.73 (6.31) and $b^{*} 11.25$ (7.13) were higher compared to those of the incisors.

Similarly, the $\mathrm{L}^{*}$ mean value for the female maxillary central incisor 87.15 (4.27) was higher than that of the mandibular central incisor 81.75 (5.23), however, their $a^{*}-0.68(2.10)$ and $b^{*} 2.50$ (4.03) means were less than those of the lower incisor 1.16 (2.28) and 2.98 (3.67) respectively. The female attached gingiva $\mathrm{L}^{*}$ mean value 61.72 (8.72) was less than those of the incisors, however, its means of $a^{*} 22.79(6.16)$ and $b^{*} 6.69$ (4.80) were higher compared to those of the incisors. The oneway ANOVA analysis showed that these differences among the means of the color coordinates were statistically significant as seen in table 2 .

The Pearson correlation coefficient ( $\mathrm{r}$ ), as seen in table 3, among the color coordinates of the male patients' maxillary central incisors and attached gingiva revealed a weak positive correlation between the $\mathrm{L}^{*}$ of the maxillary central incisors and the that of the attached gingiva $(r=0.342, p=0.000)$ as seen in figure 2 where the data showed a positive trend in distribution but not in a close proximity. A strong positive correlation between the maxillary incisors and attached gingiva $b^{*}(r=0.655, p=0.000)$ was noted, as seen in figure 4 , where the data showed a positive trend with a close proximity in distribution. However, there was no statistically significant relationship between the color determinant $\mathrm{a}^{*}$ of the maxillary incisors and the attached gingiva.

On the other hand, the male patients' mandibular central incisors color attributes $\mathrm{L}^{*}, \mathrm{a}^{*}$, and $\mathrm{b}^{*}$ had a positive correlation with those of the attached gingiva as seen in table 3 , where the $\mathrm{L}^{*}$ coordinate correlation was moderately positive $(\mathrm{r}=0.451, \mathrm{p}=$ $0.000)$ as seen in data distribution in figure 2 . The $\mathrm{a}^{*}$ coordinate correlation was a weak positive $(\mathrm{r}=$ $0.255, \mathrm{p}=0.01$ ) as seen in data distribution in figure 3 . And the "b" coordinate showed a strong positive 
correlation $(\mathrm{r}=0.619, \mathrm{p}=0.000)$ as seen in data distribution in figure 4.

Table 4 showed weak to moderate correlations among the color coordinates of female patients' central incisors and attached gingiva. The female maxillary central incisors $\mathrm{L}^{*}$ had a moderate strong positive correlation with that of the attached gingiva $\left(\mathrm{r}=0.504, \mathrm{p}=0.000\right.$, fig. 5), the $\mathrm{a}^{*}$ coordinate had a weak positive correlation with that of the attached gingiva ( $r=0.364, p=0.000$, fig. 6), and the $b^{*}$ coordinate also had a weak positive correlation with that of the attached gingiva $(r=0.236, p=0.016$, fig . 7). The female patients' mandibular central incisors color attribute $\mathrm{L}^{*}$ had a weak positive correlation with that of the attached gingiva $(r=0.312, \mathrm{p}=$ 0.002 , fig. 5), the $\mathrm{a}^{*}$ coordinate had a weak negative correlation with that of the attached gingiva $(r=$
$-0.335, \mathrm{p}=0.002$, fig. 6 ), and the $\mathrm{b}^{*}$ coordinate also had a weak positive correlation with that of the attached gingiva $(r=0.306, p=0.002$, fig. 7$)$.

The multiple regression predicted certain percentages of the values of the tooth color coordinates based on the values of gingival color. For the male patients' maxillary central incisors, the coefficient of determination $\left(\mathrm{r}^{2}\right.$ in table 3 ) could only predict $11 \%$ of total variability found for $\mathrm{L}^{*}$, and $43 \%$ of the $b^{*}$, and for the male mandibular central incisors, $20 \%$ for $\mathrm{L}^{*}, 5 \%$ for the $\mathrm{a}^{*}$, and $38 \%$ of the $\mathrm{b}^{*}$. While for female patients' predicted values of the tooth color $\left(\mathrm{r}^{2}\right.$ in table 4$)$ the maxillary central incisors had $25 \%$ for $\mathrm{L}^{*}, 13 \%$ for the $\mathrm{a}^{*}$, and $5 \%$ for the $b^{*}$, on the other hand, the predicted values for the female patients' mandibular central incisors color were $9 \%$ for $\mathrm{L}^{*}, 11 \%$ for the $\mathrm{a}^{*}$, and $9 \%$ for the $\mathrm{b}^{*}$.

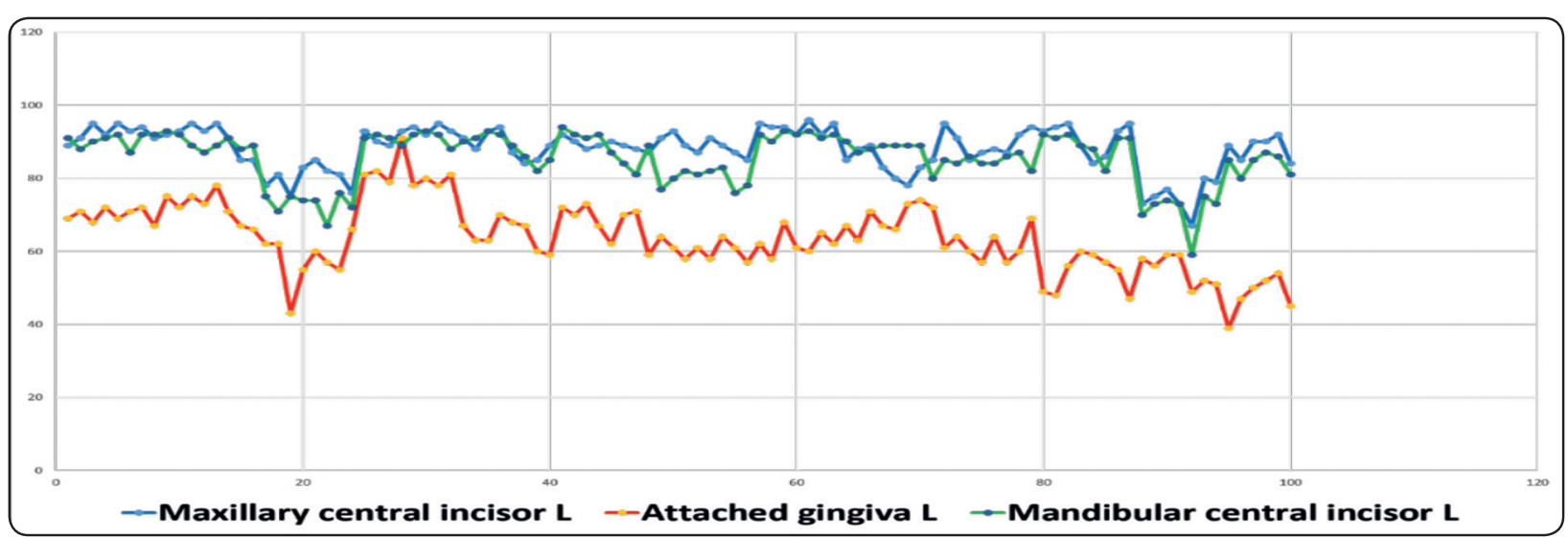

Fig. (2) Distribution of color coordinate L* in male patients.

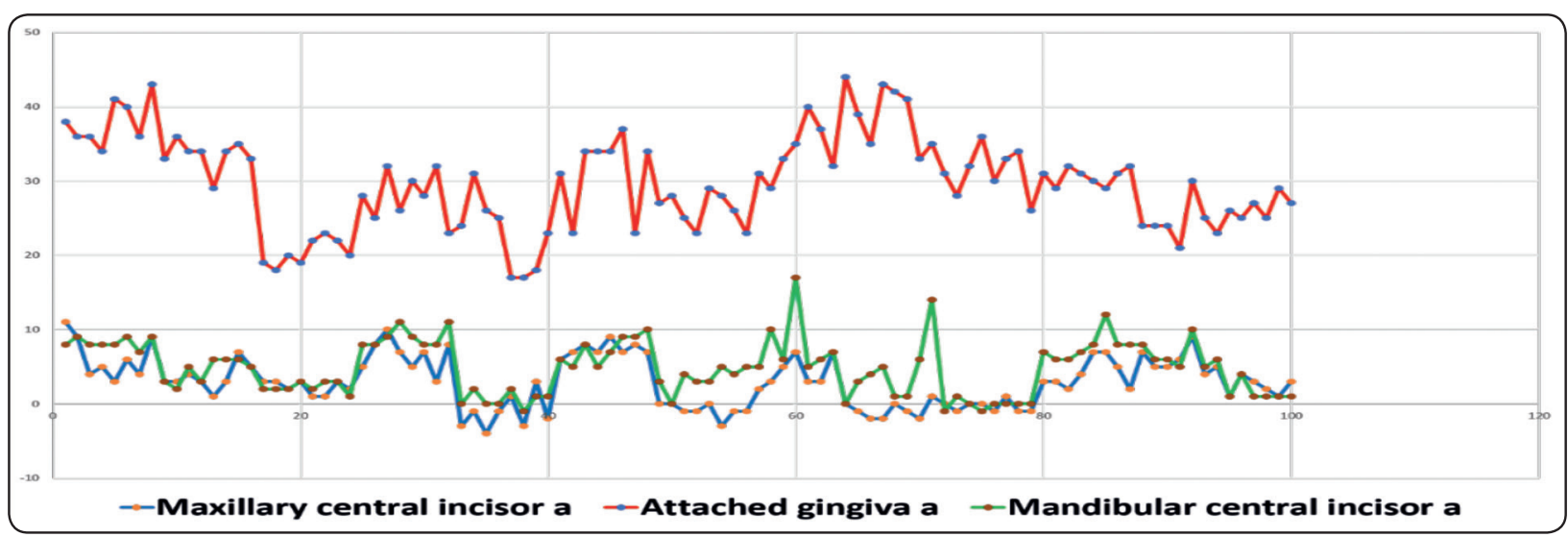

Fig. (3) Distribution of color coordinate a* in male patients. 


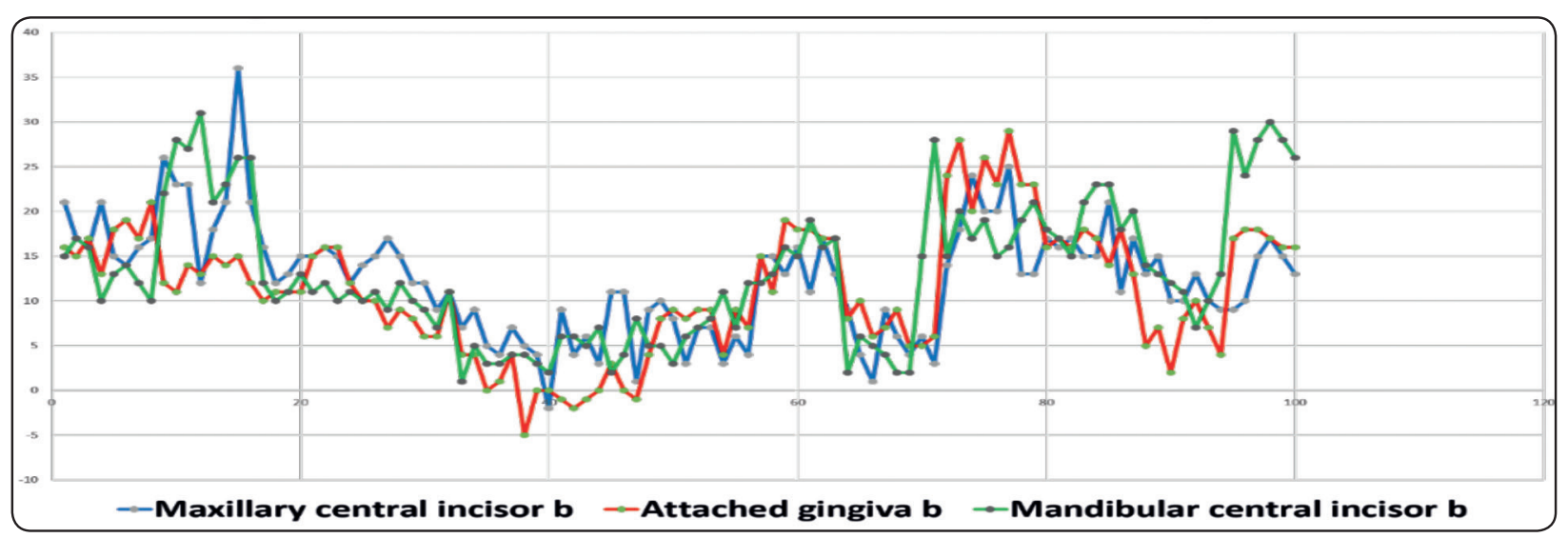

Fig. (4) Distribution of color coordinate b* in male patients.

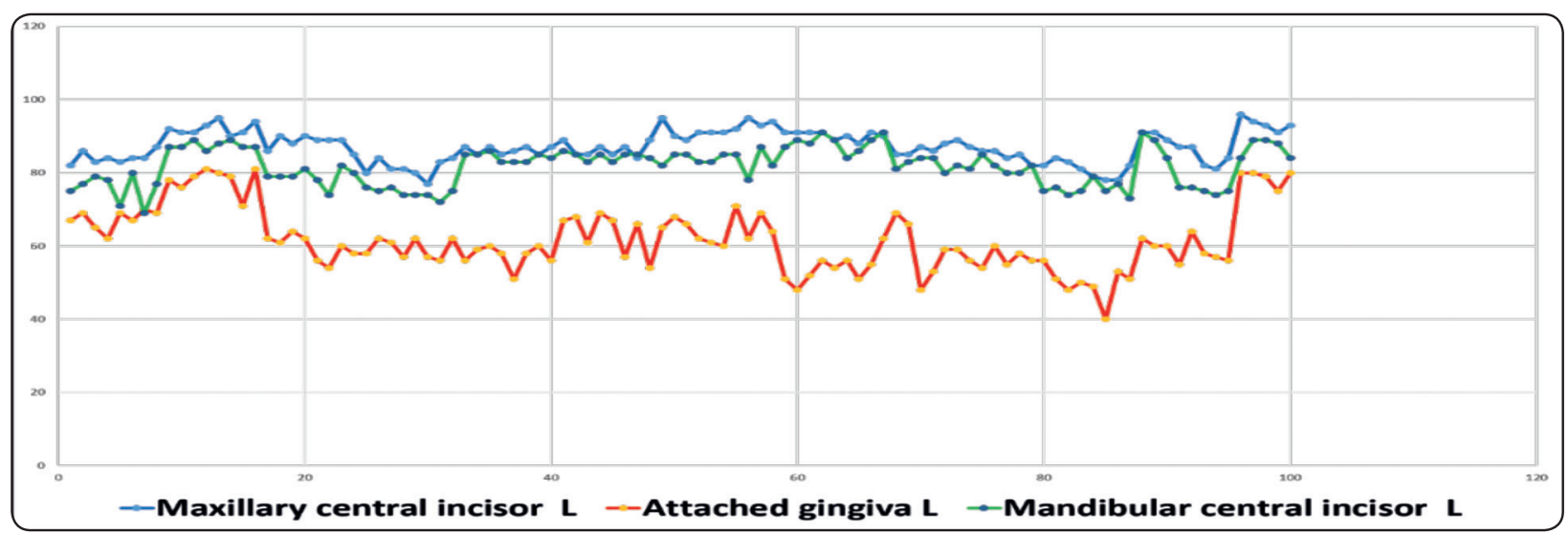

Fig. (5) Distribution of color coordinate $L^{*}$ in female patients.

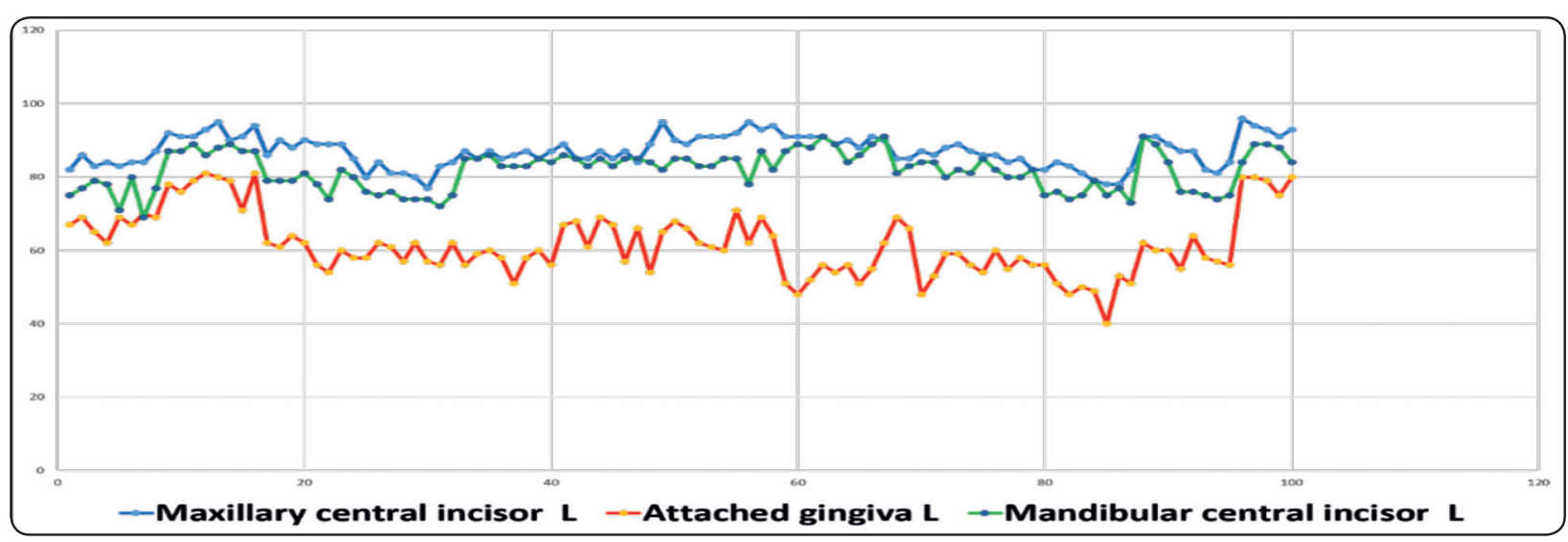

Fig. (6) Distribution of color coordinate $a^{*}$ in female patients. 


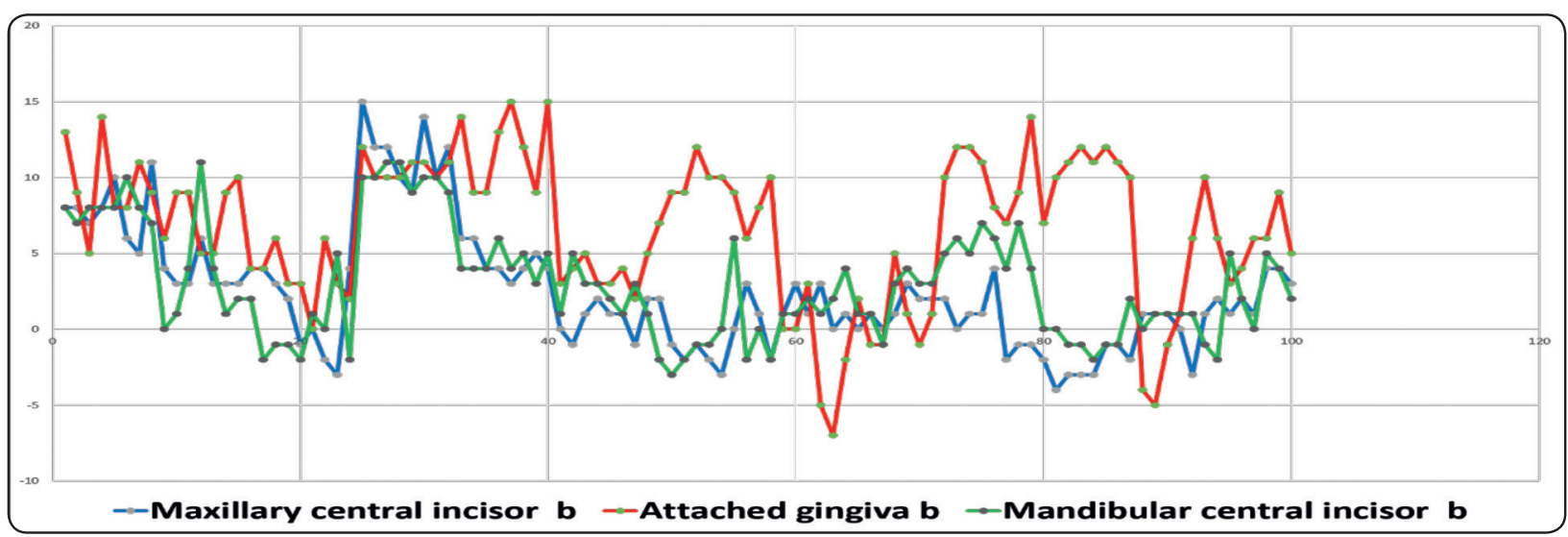

Fig. (7) Distribution of color coordinate $b^{*}$ in female patients.

TABLE (1) The mean values of the color coordinates $\mathrm{L}^{*}, \mathrm{a}^{*}$, and $\mathrm{b}^{*}$ for the maxillary central incisors, mandibular central incisors, and maxillary attached gingiva.

\begin{tabular}{|c|c|c|c|c|c|c|}
\hline & & $\mathrm{N}$ & Mean & $\begin{array}{c}\text { Standard } \\
\text { Deviation }\end{array}$ & Minimum & Maximum \\
\hline \multirow{4}{*}{ Male maxillary central incisor } & $\mathrm{L}$ & 100 & 88.16 & 5.967 & 67 & 96 \\
\hline & $\mathrm{a}$ & 100 & 3.01 & 3.448 & -4 & 11 \\
\hline & $\mathrm{b}$ & 100 & 12.54 & 6.306 & -2 & 36 \\
\hline & Total & 300 & 34.57 & 38.533 & -4 & 96 \\
\hline \multirow{4}{*}{ Male mandibular central incisor } & $\mathrm{L}$ & 100 & 85.49 & 7.102 & 59 & 94 \\
\hline & $\mathrm{a}$ & 100 & 4.89 & 3.648 & -1 & 17 \\
\hline & $\mathrm{b}$ & 100 & 13.21 & 7.715 & 1 & 31 \\
\hline & Total & 300 & 34.53 & 36.813 & -1 & 94 \\
\hline \multirow{4}{*}{ Male attached gingiva } & $\mathrm{L}$ & 100 & 63.74 & 9.355 & 39 & 91 \\
\hline & $\mathrm{a}$ & 100 & 29.73 & 6.318 & 17 & 44 \\
\hline & $\mathrm{b}$ & 100 & 11.25 & 7.130 & -5 & 29 \\
\hline & Total & 300 & 34.91 & 23.091 & -5 & 91 \\
\hline \multirow{4}{*}{ Female maxillary central incisor } & $\mathrm{L}$ & 100 & 87.15 & 4.279 & 77 & 96 \\
\hline & $\mathrm{a}$ & 100 & -.68 & 2.103 & -4 & 5 \\
\hline & $\mathrm{b}$ & 100 & 2.50 & 4.031 & -4 & 15 \\
\hline & Total & 300 & 29.66 & 40.901 & -4 & 96 \\
\hline \multirow{4}{*}{ Female mandibular central incisor } & $\mathrm{L}$ & 100 & 81.75 & 5.239 & 69 & 91 \\
\hline & $\mathrm{a}$ & 100 & 1.16 & 2.282 & -2 & 8 \\
\hline & $\mathrm{b}$ & 100 & 2.98 & 3.676 & -3 & 11 \\
\hline & Total & 300 & 28.63 & 37.834 & -3 & 91 \\
\hline \multirow{4}{*}{ Female attached gingiva } & $\mathrm{L}$ & 100 & 61.72 & 8.726 & 40 & 81 \\
\hline & $\mathrm{a}$ & 100 & 22.79 & 6.167 & 3 & 40 \\
\hline & $\mathrm{b}$ & 100 & 6.69 & 4.805 & -7 & 15 \\
\hline & Total & 300 & 30.40 & 24.102 & -7 & 81 \\
\hline
\end{tabular}


TABLE (2) Statistical analysis by ANOVA

\begin{tabular}{|c|c|c|c|c|c|c|}
\hline & & $\begin{array}{l}\text { Sum of } \\
\text { Squares }\end{array}$ & $\begin{array}{l}\text { Degree of } \\
\text { freedom }\end{array}$ & Mean Square & $\mathrm{F}$ & Significance \\
\hline \multirow{3}{*}{$\begin{array}{l}\text { Male maxillary } \\
\text { central incisor }\end{array}$} & Between Groups & 435324.260 & 2 & 217662.130 & 7482.768 & .000 \\
\hline & Within Groups & 8639.270 & 297 & 29.088 & & \\
\hline & Total & 443963.530 & 299 & & & \\
\hline \multirow{3}{*}{$\begin{array}{l}\text { Male mandibular } \\
\text { central incisor }\end{array}$} & Between Groups & 392999.360 & 2 & 196499.680 & 4782.319 & .000 \\
\hline & Within Groups & 12203.370 & 297 & 41.089 & & \\
\hline & Total & 405202.730 & 299 & & & \\
\hline \multirow{3}{*}{ Male attached gingiva } & Between Groups & 141779.687 & 2 & 70889.843 & 1193.033 & .000 \\
\hline & Within Groups & 17647.700 & 297 & 59.420 & & \\
\hline & Total & 159427.387 & 299 & & & \\
\hline \multirow{3}{*}{$\begin{array}{l}\text { Female maxillary } \\
\text { central incisor }\end{array}$} & Between Groups & 496328.127 & 2 & 248164.063 & 19096.913 & .000 \\
\hline & Within Groups & 3859.510 & 297 & 12.995 & & \\
\hline & Total & 500187.637 & 299 & & & \\
\hline \multirow{3}{*}{$\begin{array}{l}\text { Female mandibular } \\
\text { central incisor }\end{array}$} & Between Groups & 423425.780 & 2 & 211712.890 & 13758.570 & .000 \\
\hline & Within Groups & 4570.150 & 297 & 15.388 & & \\
\hline & Total & 427995.930 & 299 & & & \\
\hline \multirow{3}{*}{$\begin{array}{l}\text { Female attached } \\
\text { gingiva }\end{array}$} & Between Groups & 160101.860 & 2 & 80050.930 & 1749.697 & .000 \\
\hline & Within Groups & 13588.140 & 297 & 45.751 & & \\
\hline & Total & 173690.000 & 299 & & & \\
\hline
\end{tabular}

TABLE (3) Pearson correlation coefficient (r), and the coefficient of determination $\left(r^{2}\right)$ among the color coordinates of male patients' central incisors and attached gingiva.

\begin{tabular}{|c|c|c|c|c|c|c|c|}
\hline & & $\begin{array}{c}\text { Male } \\
\text { maxillary } \\
\text { central } \\
\text { incisors L }\end{array}$ & $\begin{array}{c}\text { Male } \\
\text { maxillary } \\
\text { central } \\
\text { incisors a }\end{array}$ & $\begin{array}{c}\text { Male } \\
\text { maxillary } \\
\text { central } \\
\text { incisors b }\end{array}$ & $\begin{array}{c}\text { Male } \\
\text { mandibular } \\
\text { central } \\
\text { incisors L }\end{array}$ & $\begin{array}{c}\text { Male } \\
\text { mandibular } \\
\text { central } \\
\text { incisors a }\end{array}$ & $\begin{array}{c}\text { Male } \\
\text { mandibular } \\
\text { central } \\
\text { incisors b }\end{array}$ \\
\hline \multirow{3}{*}{$\begin{array}{c}\text { Male attached } \\
\text { gingiva } \mathrm{L}\end{array}$} & $\mathrm{r}$ & $0.342^{* *}$ & & & $0.451^{* *}$ & & \\
\hline & $\mathrm{r}^{2}$ & 0.11 & & & 0.20 & & \\
\hline & $\mathrm{p}$-value & 0.000 & & & 0.000 & & \\
\hline \multirow{3}{*}{$\begin{array}{c}\text { Male attached } \\
\text { gingiva a }\end{array}$} & $\mathrm{r}$ & & 0.124 & & & $0.255^{*}$ & \\
\hline & $\mathrm{r}^{2}$ & & 0.01 & & & 0.05 & \\
\hline & p-value & & 0.219 & & & 0.010 & \\
\hline \multirow{3}{*}{$\begin{array}{c}\text { Male attached } \\
\text { gingiva } b\end{array}$} & $\mathrm{r}$ & & & $0.655^{*}$ & & & $0.619^{*}$ \\
\hline & $r^{2}$ & & & 0.43 & & & 0.38 \\
\hline & $\mathrm{p}$-value & & & 0.000 & & & .000 \\
\hline
\end{tabular}

** Correlation is significant at the 0.01 level (2-tailed).

* Correlation is significant at the 0.05 level (2-tailed). 
TABLE (4) Pearson correlation coefficient ( $r$ ), and the coefficient of determination $\left(r^{2}\right)$ among the color coordinates of female patients' central incisors and attached gingiva.

\begin{tabular}{|c|c|c|c|c|c|c|c|}
\hline & & $\begin{array}{c}\text { Female } \\
\text { maxillary } \\
\text { central } \\
\text { incisors L }\end{array}$ & $\begin{array}{c}\text { Female } \\
\text { maxillary } \\
\text { central } \\
\text { incisors a }\end{array}$ & $\begin{array}{c}\text { Female } \\
\text { maxillary } \\
\text { central } \\
\text { incisors b }\end{array}$ & $\begin{array}{c}\text { Female } \\
\text { mandibular } \\
\text { central } \\
\text { incisors L }\end{array}$ & $\begin{array}{c}\text { Female } \\
\text { mandibular } \\
\text { central } \\
\text { incisors a }\end{array}$ & $\begin{array}{c}\text { Female } \\
\text { mandibular } \\
\text { central } \\
\text { incisors b }\end{array}$ \\
\hline \multirow{3}{*}{$\begin{array}{l}\text { Female } \\
\text { attached } \\
\text { gingiva L }\end{array}$} & $\mathrm{r}$ & $0.504^{* *}$ & & & $0.312^{* *}$ & & \\
\hline & $\mathrm{r}^{2}$ & 0.25 & & & 0.09 & & \\
\hline & p-value & 0.000 & & & 0.002 & & \\
\hline \multirow{3}{*}{$\begin{array}{l}\text { Female } \\
\text { attached } \\
\text { gingiva a }\end{array}$} & $\mathrm{r}$ & & $0.364^{* *}$ & & & $-0.335^{* *}$ & \\
\hline & $r^{2}$ & & 0.13 & & & 0.11 & \\
\hline & p-value & & 0.000 & & & 0.001 & \\
\hline \multirow{3}{*}{$\begin{array}{l}\text { Female } \\
\text { attached } \\
\text { gingiva b }\end{array}$} & $\mathrm{r}$ & & & $0.236^{* *}$ & & & $0.306^{* *}$ \\
\hline & $\mathrm{r}^{2}$ & & & 0.05 & & & 0.09 \\
\hline & p-value & & & 0.018 & & & 0.002 \\
\hline
\end{tabular}

** Correlation is significant at the 0.01 level (2-tailed).

* Correlation is significant at the 0.05 level (2-tailed).

\section{DISCUSSION}

Determination of missing anterior teeth shade is usually a subjective process that seeks references from surrounding structures such as skin of the malar region, fore head and ear lope. According to Haralur et al ${ }^{1}$, Sharma et al ${ }^{2}$, Jahangiri et $\mathrm{al}^{3}$, and Oluwole et $\mathrm{al}^{4}$ facial skin color was found to have a significant relation with teeth color as related to gender and age. Skin color was proven to be used as a guide to select shades of missing anterior teeth that would be in harmony with the patient complexion. 5,6,8,10,13-16,18,19 However, little data exists regarding the relationship between teeth and gingival color. Gingival color was found by Ghani et $\mathrm{al}^{7}$, Schnitzer at al ${ }^{29}$, Eckhard et al ${ }^{30}$, and Ho et al ${ }^{31}$ to be significantly related to skin color with no correlation to gender, and since skin color is significantly related to teeth color, the current work investigated the relationship between the gingival and teeth color in order to add the gingival color to the potential references of missing teeth color.

As proven by several studies, ${ }^{21-28}$ the spectrophotometer used in the present study was found to be consistent and more objective than the visual shade guides and helped eliminate the effect of different light sources and inter examiner bias.

In this research, the middle thirds of the labial surface of the central incisors were selected as references for these teeth colors, as they were proven by Lee et all ${ }^{11}$, and Tuncdemir et al ${ }^{12}$ to guarantee the reproducibility of spectrophotometric color measurements, being away from the translucency of the incisal edges and darkness of the cervical regions, and being flat, compared to the surface of the canines, it ensures close contact of the spectrophotometer and prevents the edge loss effect, however, this might not be a problem in the Shadepilot spectrophotometer used in this study due to its wide view acquisition. Higher $\mathrm{a}^{*}$ value of the canines as compared to both upper and lower central incisors was one more reason for selecting the central incisors. ${ }^{12}$

The registration of gingival color was done $2 \mathrm{~mm}$ apical to the zenith of the cervical margin of the maxillary central incisors. Patients with hyperpigmentation were excluded from this study, however, in dark skinned patients, relative hyperpigmentation was most frequently found in 
the interdental papilla away from the area selected for measuring the gingival color. The maxillary attached gingiva was preferred over the mandibular attached gingiva due to the smaller area of the mandibular gingiva compared to the maxillary, and due to its relatively thinner biotype which may lead to lighter color detected. ${ }^{29-33}$

To avoid the effect of age, patients selected in this study were between 20 and 30 years old, as it is generally stated that at the late 30 s skin, teeth, and gingivae begin to obtain more yellow component. Gender is another influencing factor, where women tend to have lighter teeth, and so the study included both sexes on separate basis. ${ }^{4,29-32}$

Ho et al ${ }^{31}$ found significant differences when comparing gingival color of different races, a finding that further complicated and reduced the clinical usefulness of available gingival shade guide as concluded by Ak and Kaki. ${ }^{32}$ Gingival pigmentation represented an additional challenge to gingival color esthetics, Shahna et al ${ }^{33}$ advised chemical and surgical treatments to depigment the gingivae in case they affect esthetics negatively.

The CIELAB system used to describe color in this study enabled the determination of the degree of white to black value of color as represented by the lightness $\mathrm{L}^{*}$, the degree of greenness to redness as $\mathrm{a}^{*}$ went from negative to positive, and the degree of blueness to yellowness when $b^{*}$ went from negative to positive. ${ }^{30-38}$ However, the color difference $\Delta \mathrm{E}$ was not considered in this study as its aim was to correlate the color coordinates and not to compare the color differences between the teeth and gingivae in the studied groups.

It seemed interesting to compare the relationship between the teeth and gingival color to the teeth and skin color in Saudi populations in the two studies conducted by Haralur et al ${ }^{1}$, and Haralur. ${ }^{5}$ In his first study, Haralur et al ${ }^{1}$ examined the teeth to skin relationships in a group of 75 Saudi participant, aging 20 to 50 years old, compared to other ethnic groups, He used spectrophotometer to determine teeth color, and photography to determine the color of the skin of the malar region, forehead, and ear lope, the only significant relationships found were those between the ear lope and teeth $\mathrm{L}^{*}$ and $\mathrm{a}^{*}$, where the Pearson coefficient factor values were 0.275 and -0.240 respectively, meaning that their coefficient of determination values would be 0.07 and 0.05 respectively, and accordingly, this multiple regression could only predict $7 \%$ of the teeth lightness $\mathrm{L}^{*}$, and $5 \%$ of the teeth redness. In his second study, Haralur ${ }^{5}$ used the same methodology only on Saudi populations, divided into 3 groups 75 participants each, considering the first group which had similar age to the participant in this study, the only teeth to skin significant color relationships were those between the ear lope $\mathrm{L}^{*}$, and the fore head $\mathrm{L}^{*}$, where their values were 0.218 and 0.216 respectively, and so their coefficient of determination values would be 0.04 for each, meaning that they could only predict $4 \%$ of the teeth lightness value.

On the other hand, the results of current work showed that for gingival color relationship to the male patients' maxillary central incisors, the coefficient of determination could predict $11 \%$ of the teeth lightness $\mathrm{L}^{*}$, and $43 \%$ of the yellowness $b^{*}$, and for the gingival color relationship to the male mandibular central incisors, the coefficient of determination could predict $20 \%$ of the teeth lightness $\mathrm{L}^{*}, 5 \%$ of the teeth redness $\mathrm{a}^{*}$, and $38 \%$ of the teeth yellowness $b^{*}$. While for female patients', the gingival color to teeth relationship, the predicted color values of the maxillary central incisors were $25 \%$ for $\mathrm{L}^{*}, 13 \%$ for the $\mathrm{a}^{*}$, and $5 \%$ for the $\mathrm{b}^{*}$, and the predicted values for the female patients' mandibular central incisors color were $9 \%$ for $\mathrm{L}^{*}$, $11 \%$ for the $\mathrm{a}^{*}$, and $9 \%$ for the $\mathrm{b}^{*}$.

Accordingly, this comparison showed that gingival color was more significantly related to teeth color than the facial skin, and could predict more percentages of teeth color attributes values. Although this might not be a valid comparison, due to the difference of tissues examined and methods used, Gotfredsen et al ${ }^{26}$ stated that the digital 
photography scanning, and subsequent analysis using computer software, were effective and comparable to the colorimetric systems used for tooth color determination.

Finally, some limitations of this study are worth mentioning, since they could affect the results and invite more future research. For example, the teeth color considered was only that of the central incisors, where on the other hand, gingival color can be further studied in relation to teeth with more red and yellow components such as the canines and premolars. Also, the number of participants could have been higher, even for the one province studied, and the age group studied could have been increased to involve older participants to study the effect of aging on the relationship between the colors of the central incisors and gingiva.

\section{CONCLUSION}

Within the limitations of the study, it was concluded that the significant correlation found between central incisors and gingival color sets the gingival color, in addition to the skin, as reliable guide to the selection of the shades of artificial teeth color in the absence of natural teeth.

\section{REFERENCES}

1. Haralur SB, Dibas AM, Almelhi NA, and Dhafer Ali AlQahtani DA: The Tooth and Skin Colour Interrelationship across the Different Ethnic Groups. International Journal of Dentistry Volume 2014, Article ID 146028, 6 pages. http://dx.doi.org/10.1155/2014/146028

2. SharmaV, Punia V, Khandelwal M, Punia S, Lakshmana BR: A study of relationship between skin color and tooth shade value in Population of Udaipur, Rajasthan. International Journal of Dental Clinics 2010; 2: 26-29.

3. Jahangiri L, Reinhardt SB, Mehra RV, Matheson PB: Relationship between tooth shade value and skin color: An observational study. J Prosthet Dent 2002; 87: 149-52.

4. Oluwole OD, Elizabeth BD:Relationship between Tooth Colour, Skin Colour and Age: An Observational Study in Patients at the Ibadan Dental School Afr. J. Biomed. Res. 2010; 13: 9-14
5. Haralur BS: Effect of Age on Tooth Shade, Skin Color and Skin-Tooth Color Interrelationship in Saudi Arabian Subpopulation. Journal of International Oral Health 2015; 7:33-36.

6. Gozalo-Diaz D, Johnston WM, and Wee AG: Estimating the color of maxillary central incisors based on age and gender. J Prosthet Dent 2008; 100:93-98.

7. Alrifai M, Alharby H, Zubrzycka-Wróbel J, Renata Chałas R: A comparison of anterior teeth color among Polish, Saudi and Taiwanese students of dentistry. Pol J Public Health 2016;126(3): 134-137.

8. Labban N, Al-Otaibi H, Alayed A, Alshankiti K, Al-Enizy MA: Assessment of the influence of gender and skin color on the preference of tooth shade in Saudi population. The Saudi Dental Journal. 2017; 29: 102-110.

9. Young L Jr, Glaros AG, Moore DJ, and Collins JF: Assessing shade differences in acrylic resin denture and natural teeth. J Prosth Dent. 1994; 71:575- 580.

10. Veeraganta SK, Savadi RC, Baroudi K, Nassani MZ. Differences in tooth shade value according to age, gender and skin color: A pilot study. The Journal of the Indian Prosthodontic Society. 2015 Apr;15(2):138.

11. LEE YK: Color Correlations among Six Types of Permanent Anterior Teeth Journal of Esthetic and Restorative Dentistry. 2016; 28: S5-S13.

12. Tuncdemir AR, Polat S, Ozturk C, Tuncdemir MT, GungorAY: Color differences between maxillary and mandibular incisors. European Journal of General Dentistry. 2012;1: 17-0-173.

13. Ponnaiyan D, Jegadeesan V, Perumal G, Anusha A. Correlating skin color with gingival pigmentation patterns in South Indians-A cross sectional study. Oral Health Dent Manag. 2014 Mar;13(1):132-6.

14. Salman A, Habib SR, Azad AA. Scientific and artistic principles of tooth shade selection: a review. Pakistan Oral \& Dental Journal. 2011 Jun 1;31(1).

15. Lagouvardos PE, Tsamali I, Papadopoulou C, Polyzois G. Tooth, skin, hair and eye colour interrelationships in Greek young adults. Odontology. 2013 Jan 1;101(1):75-83.

16. Rana NA, Farid H, Shinwari MS, Anwar A. Identification of tooth shade in various age groups of Pakistani population using Vita Easyshade. Cell. 2014;334:8982829. 
17. Ghani B, Jouhar R, Ahmed N. Relationship of Facial Skin Complexion with Gingiva and Tooth Shade on Smile Attractiveness. J Interdiscipl Med Dent Sci. 2016;4(205):2.

18. Pustina-Krasniqi T, Xhajanka E, Ajeti N, Bicaj T, Dula L, Lila Z. The relationship between tooth color, skin and eye color. European oral research. 2018 Jan;52(1):45-9.

19. Rekha SB, Padmasree S, Aparna N, Kumari R. Evaluation of shade Differences between Natural Anterior Teeth in Patients of Different Age Groups, Skin tone, and Gender: A Computerized Cross-sectional Study. International Journal of Scientific study. 2016 Apr 1;4(1):231-5.

20. Chu SJ, Trushkowsky RD, Paravina RD: Dental color matching instruments and systems. Review of clinical and research aspects. Journal of dentistry. 2010; 38:e 2 - e 16.

21. Lagouvardos PE, Fougia AG, Diamantopoulou SA, Polyzois GL. Repeatability and interdevice reliability of two portable color selection devices in matching and measuring tooth color. The Journal of prosthetic dentistry. 2009 Jan 1;101(1):40-5.

22. Ayash GM, Osman E, Segaan LG, Rayyan MM. Visual versus instrumental shade selection techniques. Egyptian Dental Journal. 2016 Apr;61(2011):2015.

23. Wee AG, Beatty MW, Gozalo-Diaz DJ, Kim-Pusateri S, Marx DB. Proposed shade guide for human facial skin and lip: A pilot study. The Journal of prosthetic dentistry. 2013 Aug 1;110(2):82-9.

24. Rayyan mm. Comparison of hand-held full spectrum light and two different lighting conditions on accuracy of visual tooth shade matching. Egyptian Dental Journal. 2014 apr;60(2525):2531.

25. Al-Dwairi Z, Shaweesh A, Kamkarfar S, Kamkarfar S, Borzabadi-Farahani A, Lynch E. Tooth shade measurements under standard and nonstandard illumination and their agreement with skin color. International Journal of Prosthodontics. 2014 Sep 1;27(5).

26. Gotfredsen K, Gram M, Ben Brahem E, Hosseini M, Petkov M, Sitorovic M. Effectiveness of shade measurements using a scanning and computer software system: a pilot study. Int J Oral Dent Health. 2015;1(008).

27. Pustina-Krasniqi T, Bytyçi A, Bicaj T, Ahmedi E, Dula L, Lila Z, Dragusha A, Ajeti N. The color of natural teeth investigated by visual perception and spectrophotometer. Open Journal of Stomatology. 2015 Jan 30;5(02):26.

28. Nalbant AD, Babaç YG, Türkcan İ, Yerliyurt K, Akçaboy C, Nalbant L. Examination of natural tooth color distribution using visual and instrumental shade selection methods. Balkan Journal of Dental Medicine. 2016 Jul 1;20(2):104-10.

29. Schnitzer S, Türp JC, Heydecke G. Color distribution and visual color assessment of human gingiva and mucosa: a systematic review of the literature. International Journal of Prosthodontics. 2004 May 1;17(3).

30. Eckhard T, Valero EM, Nieves JL. Labial teeth and gingiva color image segmentation for gingival health-state assessment. InConference on Colour in Graphics, Imaging, and Vision 2012 Jan 1 (Vol. 2012, No. 1, pp. 102-107). Society for Imaging Science and Technology.

31. Ho DK, Ghinea R, Herrera LJ, Angelov N, Paravina RD. Color range and color distribution of healthy human gingiva: a prospective clinical study. Scientific reports. 2015 Dec 22; 5:18498.

32. Ak B, Kaki B. Color distribution of gingiva created by color schema maker software. Eastern Journal of Medicine. 2016 Apr 1;21(2):69.

33. Shahna N, Suchetha A, Sapna N, Darshan BM, Apoorva SM. Gingival pigmentation: A review of literature. International Journal of Applied Dental Sciences 2019; 5(2): 83-91

34. Lindsey DT, Wee AG. Perceptibility and acceptability of CIELAB color differences in computer-simulated teeth. Journal of dentistry. 2007 Jul 1;35(7):593-9.

35. Joiner A, Hopkinson I, Deng Y, Westland S. A review of tooth colour and whiteness. Journal of dentistry. 2008 Jan $1 ; 36: 2-7$.

36. Vadher R, Parmar G, Kanodia S, Chaudhary A, Kaur M, Savadhariya T. Basics of Color in Dentistry: A Review. Journal of dental and medical Sciences. Septmeber. 2014;13.

37. Pecho OE, Ghinea R, Alessandretti R, Pérez MM, Della Bona A. Visual and instrumental shade matching using CIELAB and CIEDE2000 color difference formulas. Dental materials. 2016 Jan 1;32(1):82-92.

38. Pérez MM, Pecho OE, Ghinea R, Pulgar R, Della Bona A. Recent advances in color and whiteness evaluations in dentistry. Curr Dent. 2019. 1, 23-29 